\title{
Dietary patterns in pregnancy and associations with nutrient intakes
}

\author{
Kate Northstone*, Pauline M. Emmett and Imogen Rogers \\ Department of Social Medicine, University of Bristol, Bristol, UK
}

(Received 14 March 2007 - Revised 2 May 2007 - Accepted 29 June 2007)

Despite the recent popularity in the use of dietary patterns to investigate diet-disease associations, the associations between dietary patterns and nutrient intakes have not been fully explored. This paper determines the linear and non-linear associations between estimated nutrient intake (considered as both absolute and relative intake) and distinct dietary patterns, obtained during the third trimester of pregnancy using principal components analysis (PCA). It also examines the proportion of variability explained by the patterns in food and nutrient intakes. Pregnant women were asked to record the frequency of consumption of a variety of food items as part of regular self-completion questionnaires, the primary source of data collection in the Avon Longitudinal Study of Parents and Children, 12035 cases were available. Individual dietary components were identified using PCA and scores on these components were related to estimated nutrient intakes. Five individual dietary patterns were established to best describe the types of diet being consumed in pregnancy. Scores on the 'processed' and 'confectionery' patterns were negatively related to the estimated intake of most nutrients with the exception of energy, fats and sugars, which increased with higher scores. Scores on the 'health-conscious' and 'traditional' components showed positive linear relationships with all nutrients. The results presented here suggest that dietary patterns adequately characterize dietary intake. There is, therefore, potential for dietary patterns to be used as a valid tool in assessing the relationship between diet and health outcomes, and dietary pattern scores could be used as covariates in specific nutrient-disease studies.

Dietary patterns: Pregnancy: PCA: ALSPAC: Nutrient intake: Diet

Despite the recent increase in the use of principal components analysis (PCA) to identify dietary patterns in epidemiological studies, little consideration has been paid to the associations between these patterns and actual nutrient intake. This is an important methodological issue, which merits more attention. There is much debate over the usefulness of dietary patterns obtained using PCA, primarily due to the exploratory nature of the method and the lack of repeatability between studies $^{1-4}$. However, the use of dietary patterns to assess diet-disease associations overcomes the inherent issue of the substantial inter-correlations between individual food and nutrient intakes. While dietary patterns may better quantify dietary choices and give greater insight into overall lifestyle choices, it is important to determine whether these dietary patterns adequately characterize actual dietary intake and whether they are a useful tool in nutritional epidemiology.

Several studies have examined the associations between dietary patterns and a variety of nutrients ${ }^{5-10}$. To date, there has not been a comprehensive investigation of a wide profile of nutrients. Moreover, there are inconsistencies in the methodologies that have been employed by these studies to examine the associations. One study to date has paid significant attention to the relationship between dietary patterns and nutrient intakes, focusing in particular on the ability of the PCA solution to account for the variation in food and nutrient intakes ${ }^{5}$. They found that their PCA solution accounted for a large proportion of the variance of absolute nutrient intake for the majority of nutrients and foods they studied. However, they did not report the proportion of variance explained by their dietary patterns using relative nutrient intake (adjusted for energy). This and other studies that have reported associations between dietary patterns and nutrient intake all used correlation coefficients to measure such associations ${ }^{5-8}$. However, this only measures the strength of any linear relationship and it is possible that other relationships exist. Only two other studies have assessed mean nutrient intakes according to categories of dietary patterns, ${ }^{9,10}$.

The aim of the present study is to examine the relationships between dietary patterns obtained by PCA and estimated nutrient intakes in a large contemporary cohort of pregnant women, in order to build on and add to the knowledge that already exists regarding these relationships. This study will consider a comprehensive list of micro- and macronutrients, which will be treated as both absolute and relative intakes. Both linear and non-linear relationships will be assessed and the proportion of variance explained by the dietary patterns will be presented.

\section{Subjects and methods}

The Avon Longitudinal Study of Parents and Children (ALSPAC) is an ongoing population-based study designed to investigate the effects of environmental, genetic and other influences on the health and development of children ${ }^{11}$. Pregnant women resident in the former Avon health authority in South-West England with an expected delivery date between 
1 April 1991 and 31 December 1992 were eligible for the study and a total cohort of 14541 pregnancies were enrolled. Ethical approval for the study was obtained from the ALSPAC law and ethics committee and Local Research Ethics Committees. Compared with the 1991 National Census data of mothers with infants under 1 year who were resident in the county of Avon, the ALSPAC sample had a slightly greater proportion of mothers who were married or cohabiting, who were owner-occupiers and who had a car in the household. The study had a smaller proportion of ethnic minority mothers. See http://www.alspac.bris.ac.uk for more detailed information on ALSPAC.

The present study was based on a self-completion questionnaire completed at 32 weeks gestation, which enquired about the frequency of consumption of forty-three different foods and drinks. The woman was given the following options to indicate how often she was currently consuming each food type: (i) never or rarely; (ii) once in 2 weeks; (iii) one to three times per week; (iv) four to seven times per week; (v) more than once per $d$. In addition, women were asked to record how many cups of tea or coffee, the number of glasses of cola and the number of slices of bread that they usually consumed daily. The usual type of bread (white or other) used was also recorded. This FFQ has been shown to produce mean nutrient intakes ${ }^{12}$ similar to those obtained for women in the British National Diet and Nutritional survey for adults ${ }^{13}$. The specific question on the frequency of oily fish consumption has also been validated by comparison with the erythrocyte fatty acid composition of pregnancy blood samples. The red blood cell DHA content increased significantly with increasing frequency of consumption of oily fish $(P<0 \cdot 001)^{14}$.

The data were numerically transformed into times consumed per week as follows: (i) 0 ; (ii) $0 \cdot 5$; (iii) $2 \cdot 0$; (iv) $5 \cdot 5$; v) 10.0 times per week, to apply quantitative meaning to the frequency categories. Additionally, all data were standardized by subtracting the mean and dividing by the standard deviation for each variable, since tea, coffee, cola and bread were measured on a different scale to the other variables.

Daily nutrient intakes were estimated from the FFQ described earlier using the 5th edition of McCance and Widdowson's 'The Composition of Food' and supplements ${ }^{15-21}$ based on standard portion sizes ${ }^{22}$. More detailed information on the methodology is published elsewhere ${ }^{12}$.

\section{Statistical methods}

The PCA used here has been described in detail elsewhere ${ }^{23}$. Briefly, PCA with varimax rotation ${ }^{24-25}$ was performed on the forty-four standardized food items. The number of components that best represented the data was chosen on the basis of the interpretability of the factor loading structure and the scree plot of the proportions of variance explained by each factor ${ }^{26}$. Using the latter method, a bend is usually discernible in the scree plot where the proportions of variance explained trails off. The factors that best reduce the dimensionality of the data are chosen to be those that are above the bend.

Scores were created for each woman for each of the components identified; these were calculated by multiplying the factor loadings by the corresponding standardized value for each food and summing across the food items. Each resulting component score has a mean of 0 and a higher score indicates closer adherence to that dietary pattern. Foods with loadings above 0.3 on a component were considered to have a strong association with that component and were deemed to be the most informative in describing the dietary patterns. Women were excluded from the PCA if they had more than ten dietary items missing. If ten or fewer items were missing, the assumption was made that the woman never consumed the item and it was given a value of 0 .

The PCA was repeated in two randomly selected split-half samples and the results were highly comparable, both in terms of the factor loadings and the component scores obtained; the original solutions were therefore retained.

Two sets of analyses were performed to determine the associations between dietary pattern scores and nutrient intake. First, the dietary pattern scores were considered as continuous variables and Pearson's correlation coefficients were calculated between these scores and absolute nutrient intake. Additionally, partial correlation coefficients were obtained, which adjusted the nutrients for the effects of energy intake and therefore represented the associations between the dietary patterns and relative nutrient intake. The proportions of variance explained by the dietary pattern scores were calculated for absolute and energy-adjusted nutrient intake and for individual foods by summing the squared correlations for each nutrient ${ }^{27}$. Second, the component scores were split into quintiles. The general linear model option in SPSS was employed to obtain parameter estimates. These estimates were adjusted for energy by including energy intake as a covariate in each model. The parameter estimates indicate how much the nutrient intakes increased or decreased according to each increasing quintile of dietary pattern score, as the lowest quintile score was used as the reference category. The parameter estimates are presented as $95 \%$ CI. For the vast majority of associations examined, the $P$ values were $<0.0001$; therefore, only $P$ values greater than this are presented in the tables.

All analyses were performed using SPSS for Windows v.12.0.1 (SPSS Inc., Chicago, IL, USA).

\section{Results}

The questionnaire completed at 32 weeks gestation was returned by 12436 women ( $85.5 \%$ of the original sample, many of these had already been lost due to miscarriage). Of these, 12053 $(96.9 \%)$ had sufficient dietary data available for the PCA.

\section{Dietary components identified}

Five dietary components were chosen to best describe the dietary patterns of the women, explaining $32.7 \%$ of the variance. Table 1 shows the factor loadings obtained. The first component had high loadings on salad, fruit, rice, pasta, oat- and bran-based breakfast cereals, fish, pulses, fruit juices and non-white bread and was labelled 'health conscious'. The second component loaded highly on all types of vegetables and red meat and poultry and was labelled 'traditional' in line with the familiar British 'meat and two veg' diet. The third component loaded highly on high-fat, processed foods, such as meat pies, sausages and burgers, fried foods, pizza, chips and crisps and was therefore described as 'processed'. The fourth component, labelled 'confectionery' was characterized by high intakes of chocolate and sweets and other foods 
Table 1. Factor loadings of various food items in the five principal dietary components identified* in 12053 pregnant women based on a FFQ $\dagger$

\begin{tabular}{|c|c|c|c|c|c|c|}
\hline Food item (Variance explained) & $\begin{array}{c}\text { 'Health conscious' } \\
(10.6 \%)\end{array}$ & $\begin{array}{c}\text { 'Traditional' } \\
(8.2 \%)\end{array}$ & $\begin{array}{c}\text { 'Processed' } \\
(4.9 \%)\end{array}$ & $\begin{array}{c}\text { 'Confectionery' } \\
(4.0 \%)\end{array}$ & $\begin{array}{c}\text { 'Vegetarian' } \\
(3.6 \%)\end{array}$ & $\%$ Variance explained \\
\hline White bread & -0.535 & 0.075 & 0.367 & 0.080 & -0.018 & $42 \cdot 7$ \\
\hline Non-white bread & 0.615 & -0.049 & -0.323 & -0.057 & 0.032 & 48.9 \\
\hline Bran-based cereal & 0.365 & 0.092 & -0.126 & -0.004 & 0.009 & $15 \cdot 8$ \\
\hline Oat-based cereal & 0.297 & 0.113 & -0.039 & 0.050 & 0.140 & 12.5 \\
\hline Other breakfast cereal & -0.110 & -0.015 & 0.139 & 0.221 & -0.082 & $8 \cdot 7$ \\
\hline Biscuits & $0 \cdot 108$ & 0.023 & -0.007 & 0.603 & -0.108 & $38 \cdot 8$ \\
\hline Crispbreads/crackers & 0.218 & 0.088 & -0.010 & 0.052 & 0.156 & 8.2 \\
\hline Puddings (expand) & 0.265 & 0.064 & 0.124 & 0.389 & -0.112 & $25 \cdot 4$ \\
\hline Cakes/buns & 0.202 & 0.004 & 0.086 & 0.559 & -0.080 & $36 \cdot 7$ \\
\hline Poultry & 0.270 & 0.223 & 0.121 & 0.023 & -0.535 & $42 \cdot 4$ \\
\hline Red meat & 0.147 & 0.219 & 0.166 & 0.101 & -0.596 & $46 \cdot 3$ \\
\hline Meat pies & -0.105 & 0.032 & 0.538 & 0.087 & -0.118 & $32 \cdot 3$ \\
\hline Offal & 0.087 & 0.091 & 0.248 & -0.066 & 0.087 & 8.9 \\
\hline Sausages, burgers & -0.091 & -0.062 & 0.565 & 0.029 & -0.169 & 36.1 \\
\hline Fried foods & -0.094 & 0.001 & 0.574 & 0.164 & -0.009 & 36.5 \\
\hline Pizza & 0.233 & -0.105 & 0.349 & 0.104 & 0.105 & $19 \cdot 8$ \\
\hline Fish & 0.457 & 0.155 & 0.133 & -0.075 & -0.018 & $25 \cdot 7$ \\
\hline Eggs & 0.278 & 0.090 & 0.403 & -0.027 & -0.016 & 24.9 \\
\hline Cheese & 0.443 & 0.078 & 0.053 & 0.122 & 0.026 & $22 \cdot 1$ \\
\hline Meat substitutes (soya, tofu, etc) & $0 \cdot 180$ & 0.066 & 0.124 & -0.028 & 0.577 & $38 \cdot 6$ \\
\hline Pulses & 0.356 & 0.146 & 0.006 & -0.055 & 0.565 & $47 \cdot 0$ \\
\hline Nuts & 0.278 & 0.116 & 0.051 & 0.052 & 0.531 & $37 \cdot 8$ \\
\hline Chips & -0.255 & -0.057 & 0.561 & 0.235 & -0.036 & 44.0 \\
\hline Roast potatoes & -0.271 & 0.225 & 0.388 & 0.154 & -0.165 & $32 \cdot 6$ \\
\hline Potatoes (not chips) & 0.254 & 0.321 & 0.104 & 0.070 & -0.219 & $23 \cdot 1$ \\
\hline Pasta & 0.578 & 0.045 & 0.136 & -0.070 & 0.121 & 37.4 \\
\hline Rice & 0.543 & 0.078 & 0.125 & -0.120 & 0.063 & 33.5 \\
\hline Baked beans & 0.004 & 0.049 & 0.413 & 0.081 & 0.045 & $18 \cdot 2$ \\
\hline Leafy green vegetables & 0.045 & 0.809 & 0.011 & -0.015 & 0.041 & $65 \cdot 8$ \\
\hline Other green vegetables & 0.147 & 0.799 & -0.043 & -0.004 & 0.054 & 66.5 \\
\hline Carrots & 0.178 & 0.704 & -0.020 & 0.023 & 0.008 & $52 \cdot 8$ \\
\hline Other root vegetables & 0.084 & 0.606 & 0.018 & 0.003 & 0.106 & 38.6 \\
\hline Peas & 0.174 & 0.352 & 0.190 & 0.063 & -0.104 & 20.5 \\
\hline Salad & 0.420 & 0.212 & -0.078 & -0.022 & 0.100 & $23 \cdot 8$ \\
\hline Fresh fruit & 0.518 & 0.182 & -0.229 & 0.090 & 0.005 & $36 \cdot 2$ \\
\hline Fruit juice & 0.488 & 0.079 & -0.090 & 0.085 & 0.057 & $26 \cdot 3$ \\
\hline Cola & -0.209 & -0.081 & 0.221 & 0.142 & 0.051 & $12 \cdot 2$ \\
\hline Tea & -0.100 & 0.078 & 0.156 & 0.029 & -0.037 & 4.3 \\
\hline Coffee & -0.161 & 0.053 & 0.105 & 0.002 & -0.037 & $4 \cdot 1$ \\
\hline Herbal tea & 0.186 & 0.068 & -0.085 & -0.057 & 0.302 & $14 \cdot 1$ \\
\hline Sweets & -0.098 & 0.071 & 0.069 & 0.514 & 0.061 & $28 \cdot 7$ \\
\hline Chocolate & 0.000 & 0.022 & 0.036 & 0.717 & 0.058 & 51.9 \\
\hline Chocolate bars & -0.085 & -0.020 & 0.096 & 0.749 & 0.021 & $57 \cdot 8$ \\
\hline Crisps & -0.101 & -0.041 & 0.292 & 0.381 & 0.004 & $24 \cdot 2$ \\
\hline
\end{tabular}

* Loadings above 0.3 are shown in bold.

†For details of subjects and procedures, see Subjects and methods.

with high sugar content such as biscuits, cakes and other puddings. Finally, the fifth component loaded highly on meat substitutes, pulses, nuts and herbal tea and high negative loadings were seen with red meat and poultry and was therefore labelled 'vegetarian'.

The proportion of variance in food intake explained by the patterns was over $50 \%$ for leafy green and other green vegetables, carrots, chocolate, chocolate bars and crisps. Over $40 \%$ of the variability was explained for white and nonwhite bread, red meat, poultry, pulses and chips.

\section{Association with estimated weekly nutrient intakes}

Table 2 shows the correlations between the dietary pattern scores and estimated nutrient intakes, both absolute and energy adjusted, by presenting partial correlation coefficients. Particularly strong positive correlations were evident between the 'health-conscious' pattern and absolute intakes of protein, $\mathrm{Mg}$, niacin, $\mathrm{K}$, fibre, thiamine, vitamins $\mathrm{B}_{6}$ and $\mathrm{C}, \mathrm{Fe}, \mathrm{Zn}, \mathrm{Na}$ and folate. These correlations were only slightly reduced after adjustment for energy intake. Absolute intakes of carotene, $\mathrm{K}$, vitamins $\mathrm{B}_{6}$ and $\mathrm{C}$ were highly correlated with the 'traditional' pattern and remained after adjustment for energy intake. The 'processed' pattern was positively correlated with absolute intakes of energy, monounsaturated and saturated fats, protein, carbohydrates and $\mathrm{Na}$. Once adjusted for energy, these relationships lessened. The 'confectionery' pattern showed the strongest association with absolute energy intake and energy-adjusted sugar intake. This pattern was strongly negatively associated with the intake of protein, $\mathrm{Zn}$ and $\mathrm{Na}$ after adjustment for energy. No strong associations were evident between the 'vegetarian' pattern and any of the nutrients, with the exception of protein, niacin and Zn (after energy adjustment), which were negatively associated. 
Table 2. Pearson's correlation coefficients between dietary pattern scores and daily absolute nutrient intakes and partial correlation coefficients between dietary pattern scores and weekly nutrient intakes adjusting for energy intake (presented as adjusted)§॥

\begin{tabular}{|c|c|c|c|c|c|c|c|c|c|c|c|c|}
\hline \multirow[b]{2}{*}{ Nutrient } & \multicolumn{2}{|c|}{ 'Health-conscious' } & \multicolumn{2}{|c|}{ 'Traditional' } & \multicolumn{2}{|c|}{ 'Processed' } & \multicolumn{2}{|c|}{ 'Confectionery' } & \multicolumn{2}{|c|}{ 'Vegetarian' } & \multicolumn{2}{|c|}{$\%$ variance explained $\ddagger$} \\
\hline & Absolute & Adjusted $†$ & Absolute & Adjusted $†$ & Absolute & Adjusted $\dagger$ & Absolute & Adjusted $†$ & Absolute & Adjusted $†$ & Absolute & Adjusted $\dagger$ \\
\hline Energy & 0.319 & & 0.174 & & 0.475 & & 0.548 & & -0.067 & & $66 \cdot 2$ & \\
\hline Total fat & 0.210 & $-0 \cdot 186$ & 0.098 & $-0 \cdot 136$ & 0.532 & 0.273 & 0.522 & 0.081 & -0.077 & -0.038 & 61.5 & $13 \cdot 6$ \\
\hline Protein & 0.564 & 0.544 & 0.304 & 0.279 & 0.402 & 0.040 & 0.217 & -0.449 & -0.266 & -0.357 & $69 \cdot 0$ & $70 \cdot 4$ \\
\hline Monounsaturated fat & 0.202 & -0.229 & 0.104 & -0.135 & 0.563 & 0.359 & 0.517 & 0.052 & -0.069 & $-0.020^{\star}$ & $64 \cdot 1$ & $20 \cdot 3$ \\
\hline Polyunsaturated fat & 0.308 & 0.152 & 0.119 & $0.017^{\star}$ & 0.293 & $0.010^{\star *}$ & 0.208 & -0.184 & 0.068 & 0.136 & $24 \cdot 3$ & $7 \cdot 6$ \\
\hline Saturated fat & 0.103 & -0.322 & 0.074 & -0.136 & 0.451 & 0.110 & 0.521 & 0.134 & -0.102 & -0.084 & $50 \cdot 1$ & 15.9 \\
\hline Carbohydrates & 0.253 & -0.131 & 0.147 & -0.044 & 0.374 & -0.215 & 0.573 & 0.206 & $0.006^{\star \star}$ & 0.189 & 55.4 & $14 \cdot 3$ \\
\hline Sugar & 0.050 & -0.283 & 0.096 & -0.046 & $0 \cdot 190$ & -0.260 & 0.639 & 0.417 & $-0.007^{\star *}$ & 0.061 & $45 \cdot 6$ & $32 \cdot 7$ \\
\hline Fibre & 0.603 & 0.545 & 0.384 & 0.357 & 0.103 & -0.276 & 0.173 & -0.253 & 0.127 & 0.215 & 56.8 & $61 \cdot 1$ \\
\hline $\mathrm{K}$ & 0.476 & 0.393 & 0.395 & 0.445 & 0.359 & -0.056 & 0.375 & $-0 \cdot 151$ & -0.092 & -0.064 & $66 \cdot 1$ & 38.3 \\
\hline $\mathrm{Na}$ & 0.418 & 0.292 & 0.128 & -0.036 & 0.503 & 0.216 & 0.297 & -0.367 & -0.043 & 0.025 & 53.4 & 26.9 \\
\hline $\mathrm{Ca}$ & 0.379 & 0.221 & 0.197 & 0.100 & 0.278 & -0.151 & 0.317 & -0.191 & 0.048 & 0.155 & $36 \cdot 3$ & $14 \cdot 2$ \\
\hline $\mathrm{Mg}$ & 0.639 & 0.631 & 0.281 & 0.230 & $0 \cdot 162$ & -0.321 & 0.288 & -0.210 & 0.097 & 0.218 & $60 \cdot 6$ & 64.6 \\
\hline $\mathrm{Fe}$ & 0.593 & 0.560 & 0.288 & 0.241 & 0.218 & -0.224 & 0.289 & -0.207 & $0.025^{\star}$ & 0.110 & $56 \cdot 6$ & $47 \cdot 7$ \\
\hline $\mathrm{Zn}$ & 0.596 & 0.590 & 0.296 & 0.261 & 0.312 & -0.114 & 0.247 & -0.358 & -0.219 & -0.270 & 64.9 & $63 \cdot 0$ \\
\hline Vitamin C & 0.555 & 0.501 & 0.482 & 0.457 & -0.096 & -0.307 & 0.124 & -0.076 & $0.025^{\star *}$ & 0.050 & $56 \cdot 6$ & $56 \cdot 2$ \\
\hline Folate & 0.530 & 0.450 & 0.497 & 0.521 & 0.165 & -0.238 & 0.237 & -0.214 & $0.015^{\star \star}$ & 0.081 & $61 \cdot 2$ & $58 \cdot 3$ \\
\hline Carotene & 0.252 & 0.183 & -0.764 & 0.756 & -0.029 & -0.183 & 0.036 & -0.135 & 0.012 & $0.030^{*}$ & 64.9 & $65 \cdot 8$ \\
\hline Retinol & 0.101 & $-0.024^{\star}$ & 0.092 & $0.028^{*}$ & 0.295 & 0.140 & 0.055 & -0.199 & -0.049 & $-0.025^{\star}$ & $11 \cdot 1$ & $6 \cdot 1$ \\
\hline Vitamin E & 0.289 & 0.153 & 0.142 & 0.062 & $0 \cdot 142$ & -0.137 & 0.184 & -0.138 & 0.111 & 0.171 & $17 \cdot 0$ & $9 \cdot 4$ \\
\hline Thiamine & 0.551 & 0.490 & 0.344 & 0.322 & 0.204 & -0.237 & 0.237 & -0.285 & -0.021 & 0.041 & $46 \cdot 4$ & $48 \cdot 3$ \\
\hline Niacin & 0.583 & 0.522 & 0.280 & 0.223 & 0.218 & -0.140 & 0.185 & -0.275 & -0.281 & -0.314 & 57.9 & $51 \cdot 6$ \\
\hline Riboflavin & 0.352 & 0.190 & 0.206 & 0.120 & 0.236 & -0.149 & 0.304 & -0.129 & -0.109 & -0.087 & 32.6 & 9.7 \\
\hline Vitamin B6 & 0.510 & 0.425 & 0.372 & 0.358 & 0.264 & -0.120 & 0.238 & -0.260 & -0.135 & -0.125 & 54.3 & $40 \cdot 6$ \\
\hline
\end{tabular}

${ }^{\star} P<0.05 ;{ }^{*} P>0.1$

†Partial correlation coefficients adjusting for energy intake.

†Proportion of variance explained, calculated as the sum of the squared correlation coefficients.

$\S$ All $P$ values $<0.0001$ unless otherwise indicated.

$\|$ For details of subjects and procedures, see Subjects and methods. 
The dietary patterns explained a substantial proportion of the variation $(>45 \%)$ of absolute intakes for nearly all nutrients, with the exception of polyunsaturated fat, total fat, $\mathrm{Ca}$, retinol, riboflavin and vitamin E. After adjusting for energy, the proportion of variation explained decreased for the majority of nutrients.

Tables 3 and 4 show the differences in macronutrient and micronutrient intakes respectively, according to increasing quintiles of each dietary pattern score. The lowest quintile scores are used as the reference category. The tables present the parameter estimates and $95 \%$ CI for the daily intakes, after adjustment for energy. As the scores on the 'health-conscious' component increased, intakes of monounsaturated, saturated and total fats, sugar and carbohydrates decreased but intakes of all other nutrients investigated increased. In general, opposite trends were seen with the 'processed' and 'confectionery' components, with the exception of energy intake, which also increased as the scores increased, and sugar, which decreased as the 'processed' score increased. The 'vegetarian' component did not show linear relationships with many of the mean nutrient intakes; for example, women in both the top and bottom quintiles had similar mean intakes of energy, carotene, $\mathrm{Fe}, \mathrm{Na}$ and folate while the middle three quintiles had substantially lower intakes.

\section{Discussion}

The present study has shown strong associations with dietary patterns identified using PCA and estimated nutrient intakes. This is the first published study to fully investigate the associations between dietary patterns and a comprehensive profile of nutrient intakes. We have presented correlations with dietary pattern scores and examined the relationship with categorical dietary pattern scores in order to assess any non-linear relationships, which would not be evident from the correlations. Finally, we have quantified the amount of variance in nutrient intake that has been explained by the dietary patterns.

Clear associations were evident between the scores obtained on the dietary components and estimated nutrient intakes. The two components that could be defined as unhealthy, "processed' and 'confectionery', were associated with increased intakes of sugar and fats and decreased intakes of all other nutrients. The 'health-conscious' and 'traditional' components, which both loaded highly on increased vegetable intake, showed positive linear relationships with all nutrients as anticipated. The associations we have found were generally consistent with previous studies ${ }^{5-10}$.

There were differences in the correlations between the dietary pattern scores and some nutrients, according to whether absolute or relative (adjusted for energy) intakes were examined. These differences were particularly evident for fats, carbohydrates and sugars, where the correlations attenuated after adjustment for energy. This is not surprising as these are the primary energy-providing nutrients. It could be argued that the original food variables should be adjusted for energy prior to entry into the PCA, as others have done ${ }^{28-30}$; such a procedure would avoid the need to examine relative nutrient intakes. We have already performed such analyses in this sample ${ }^{31}$. We concluded that it was not necessary to make energy adjustments so early in the analytical process.
It is always important to quantify the effects of energy adjustment; this is more transparent at a later stage in the analysis.

Of the three other studies that have been published to date ${ }^{32-34}$, investigating dietary patterns during pregnancy, only one has presented any variations in nutrient intakes ${ }^{34}$. Knudsen et al. identified two major dietary patterns - the 'Western diet' and the 'health conscious' patterns, which are comparable to our 'processed' and 'health conscious' patterns respectively ${ }^{34}$. The authors assigned the women into one of three mutually exclusive groups based on their scores for these two patterns ('health conscious' class if scoring in the top two quintiles for that dietary pattern but in the bottom two quintiles for 'Western diet' pattern and vice versa for the 'Western diet' class). Women in the 'health conscious' class had lower fat and energy intakes compared with those in the 'Western diet' class, while protein and carbohydrate intakes were higher in the 'health conscious' class. These results are similar to ours only in terms of fat and protein intake. However, the different methodology applied by Knudsen et al. most likely explains the differences in energy and carbohydrate intakes. No other nutrients were examined in this study. The other most analogous study to ours is that by Crozier et al., who examined dietary patterns in a nonpregnant sample of women aged 20-34 years ${ }^{8}$. Their 'prudent' and 'high energy' patterns were very similar to the 'health conscious' and 'processed' patterns that we have identified. Associations with various nutrients assessed by correlation were highly comparable to those reported here.

The proportions of variance explained by the dietary patterns in nutrient intake were generally less than those reported by Schulze et $a l^{5}$; however, they extracted seven patterns from their data, which in total explained $31 \%$ of the variance in food intake, compared with $33 \%$ of the variance explained in this dataset by five factors. Furthermore, their study did not present the proportion of variance explained for energy adjusted nutrient intake. Calculating these ourselves showed that the values were significantly reduced.

ALSPAC has previously reported that the mean intakes of energy, $\mathrm{Fe}, \mathrm{Mg}, \mathrm{K}$ and folate in this sample were below the reference nutrient intakes ${ }^{35}$ recommended for pregnant women ${ }^{12}$. The dietary patterns that have been extracted here explained $66.2 \%, 47.7 \%, 64.6 \%, 38.3 \%$ and $53.8 \%$ of the variation in intake of these nutrients respectively, a relatively large proportion. There is clearly a potential for dietary pattern analyses to aid in formulating evidenced-based dietary advice for pregnant women by recommending particular types of diet that would optimize the intake of these nutrients. The current study found clear positive associations between increasing dietary pattern scores on the 'health-conscious' and 'traditional' components and increasing intakes of these four nutrients. However, components extracted using PCA do not allow us to focus on any one particular aspect of the diet. The method of reduced rank regression ${ }^{36}$ allows the researcher to construct dietary patterns that explain the maximum amount of variation in a number of 'response' variables. In this case, the response variables would be $\mathrm{Fe}, \mathrm{Mg}, \mathrm{K}$ and folate intakes. It is important to follow this up in a future study in order to inform the current dietary recommendations for pregnant women.

Dietary intake was assessed using an unquantified FFQ, with no portion size information included. As such, the derived nutrient information may be inaccurate, compared with the 'gold 
NS British Journal of Nutrition

Table 3. Adjusted parameter estimates $(95 \% \mathrm{Cl})$ for macronutrient intakes according to quintiles of dietary pattern score, adjusted for energy intake ${ }^{*} \dagger$

\begin{tabular}{|c|c|c|c|c|c|}
\hline Macronutrient & 'Health-conscious' & 'Traditional' & 'Processed' & 'Confectionery' & 'Vegetarian' \\
\hline \multicolumn{6}{|l|}{ Energy } \\
\hline Quintile 1 & 0.00 & 0.00 & 0.00 & 0.00 & 0.00 \\
\hline Quintile 2 & $0.44(0.33,0.55)$ & $0.31(0.19,0.43)$ & $0.48(0.38,0.58)$ & $0.52(0.42,0.62)$ & $-0.95(-1.06,-0.83)$ \\
\hline Quintile 3 & $0.74(0.63,0.85)$ & $0.32(0.21,0.43)$ & $0.87(0.76,0.98)$ & $1.02(0.92,1.12)$ & $-1.09(-1.20,-0.97)$ \\
\hline Quintile 4 & $0.94(0.83,1.06)$ & $0.65(0.53,0.76)$ & $1.33(1.22,1.44)$ & $1.62(1.51,1.72)$ & $-1.11(-1.23,-0.99)$ \\
\hline Quintile 5 & $1.81(1.70,1.92)$ & $1.18(1.05,1.31)$ & $2.46(2.36,2.56)$ & $3.07(2.97,3.17)$ & $-0.77(-0.88,-0.66)$ \\
\hline \multicolumn{6}{|l|}{ Total fat } \\
\hline Quintile 1 & 0.00 & 0.00 & 0.00 & 0.00 & 0.00 \\
\hline Quintile 2 & $-0.37(-0.94,0.20)$ & $-1.30(-1.90,-0.70)$ & $2.02(1.47,2.57)$ & $0.31(-0.28,0.91)$ & $-0.35(-0.95,0.25)$ \\
\hline Quintile 3 & $-1.99(-2.57,-1.40)$ & $-1.36(-1.92,-0.80)$ & $3.28(2.68,3.88)$ & $1.29(0.69,1.88)$ & $0.28(-0.32,0.87)$ \\
\hline Quintile 4 & $-3.35(-3.95,-2.76)$ & $-2.24(-2.84,-1.64)$ & $4.48(3.88,5.09)$ & $1.68(1.06,2.30)$ & $0.61(0.01,1.21)$ \\
\hline Quintile 5 & $-5.41(-6.01,-4.82)$ & $-4.62(-5.28,-3.47)$ & $7.91(7.31,8.50)$ & $2.48(1.80,3.15)$ & $-0.70(-1.28,-0.13)$ \\
\hline \multicolumn{6}{|l|}{ Protein } \\
\hline Quintile 1 & 0.00 & 0.00 & 0.00 & 0.00 & 0.00 \\
\hline Quintile 2 & $6 \cdot 13(5 \cdot 60,6 \cdot 66)$ & $3.25(2.62,3.87)$ & $1.28(0.67,1.89)$ & $-3.17(-3.76,-2.58)$ & $-7.51(-8.08,-6.94)$ \\
\hline Quintile 3 & $9.83(9.29,10.38)$ & $4.43(3.85,5.01)$ & $1.56(0.90,2.22)$ & $-5.59(-6.18,-4.99)$ & $-10.36(-10.92,-9.79)$ \\
\hline Quintile 4 & $12.96(12.41,13.51)$ & $6 \cdot 24(5 \cdot 62,6 \cdot 87)$ & $1.59(0.92,2.26)$ & $-7.59(-8.20,-6.97)$ & $-13.37(-13.94,-12.79$ \\
\hline Quintile 5 & $17.62(17.06,18.17)$ & $10.29(9.62,10.97)$ & $1.71(1.06,2 \cdot 37)$ & $-14.44(-15.12,-13.77)$ & $-14.06(-14.07,-13.15$ \\
\hline \multicolumn{6}{|c|}{ Monounsaturated fat } \\
\hline Quintile 1 & 0.00 & 0.00 & 0.00 & 0.00 & 0.00 \\
\hline Quintile 2 & $-0.17(-0.36,0.03)$ & $-0.52(-0.72,-0.31)$ & $0.83(0.64,1.01)$ & $-0.08(-0.28,0.12)$ & $-0.15(-0.36,0.05)$ \\
\hline Quintile 3 & $-0.70(-0.90,-0.51)$ & $-0.58(-0.77,-0.39)$ & $1.31(1.11,1.51)$ & $0.07(-0.14,0.27)$ & $0.02(-0.18,0.22)$ \\
\hline Quintile 4 & $-1.36(-1.56,-1.16)$ & $-0.83(-1.04,-0.63)$ & $1.88(1.68,2.08)$ & $0.17(-0.04,0.38)$ & $0.17(-0.03,0.38)$ \\
\hline Quintile 5 & $-2.23(-2.43,-2.03)$ & $-1.60(-1.82,-1.38)$ & $3.52(3.32,3.72)$ & $0.46(0.23,0.69)$ & $\begin{array}{c}-0.18(-0.37,0.02) \\
P=0.004\end{array}$ \\
\hline \multicolumn{6}{|c|}{ Polyunsaturated fat } \\
\hline Quintile 1 & 0.00 & 0.00 & 0.00 & 0.00 & 0.00 \\
\hline Quintile 2 & $0.61(0.35,0.87)$ & $0.17(-0.10,0.44)$ & $0.29(0.03,0.54)$ & $-0.33(-0.59,-0.07)$ & $-0.01(-0.27,0.27)$ \\
\hline Quintile 3 & $1.09(0.82,1.35)$ & $0.12(-0.13,0.37)$ & $0.26(-0.02,0.54)$ & $-0.59(-0.86,-0.33)$ & $-0.12(-0.38,0.15)$ \\
\hline Quintile 4 & $1.40(1.13,1.66)$ & $0.17(-0.11,0.44)$ & $0.24(-0.04,0.52)$ & $-1.20(-1.48,-0.93)$ & $0.15(-0.12,0.42)$ \\
\hline Quintile 5 & $2.08(1.81,2.36)$ & $0.31(0.01,0.61)$ & $\begin{array}{c}0.23(-0.04,0.51) \\
P=0.214\end{array}$ & $-2.47(-2.77,-2.17)$ & $1.12(-0.87,1.38)$ \\
\hline \multicolumn{6}{|l|}{ Saturated fat } \\
\hline Quintile 1 & 0.00 & 0.00 & 0.00 & 0.00 & 0.00 \\
\hline Quintile 2 & $-1.08(-1.41,-0.75)$ & $-1.09(-1.44,-0.73)$ & $0.30(-0.04,0.63)$ & $0.33(-0.02,0.67)$ & $0.28(-0.07,0.64)$ \\
\hline Quintile 3 & $-2.54(-2.88,-2.21)$ & $-1.19(-1.52,-0.86)$ & $0.69(0.32,1.05)$ & $0.71(0.36,1.07)$ & $0.91(0.56,1.26)$ \\
\hline Quintile 4 & $-3.58(-3.92,-3.24)$ & $-1.50(-1.86,-1.15)$ & $0.96(0.59,1.33)$ & $1.26(0.89,1.62)$ & $0.82(0.46,1.18)$ \\
\hline Quintile 5 & $-5.70(-6.04,-5.36)$ & $-2.83(-3.22,-2.44)$ & $1.88(1.52,2.24)$ & $2.19(1.79,2.59)$ & $-0.48(-0.82,-0.14)$ \\
\hline \multicolumn{6}{|l|}{ Carbohydrates } \\
\hline Quintile 1 & 0.00 & 0.00 & 0.00 & 0.00 & 0.00 \\
\hline Quintile 2 & $-6.25(-7.55,-4.94)$ & $-0.87(-2.24,0.50)$ & $-4.58(-5.85,-3.32)$ & $3.41(2.09,4.72)$ & $8.62(7.29,9.94)$ \\
\hline Quintile 3 & $-7.33(-8.67,-6.00)$ & $-1.85(-3.12,-0.58)$ & $-6.97(-8.34,-5.60)$ & $4.84(3.50,6.17)$ & $10.60(9.30,11.90)$ \\
\hline Quintile 4 & $-8.38(-9.77,-7.04)$ & $-2.45(-3.82,-1.08)$ & $-8.67(-10 \cdot 10,-7 \cdot 28)$ & $6.55(5.17,7.94)$ & $13.14(11.81,14.46)$ \\
\hline Quintile 5 & $-9.47(-10.83,-8.10)$ & $-3.46(-4.95,-1.97)$ & $-14.66(-16 \cdot 01,-13 \cdot 30)$ & $14 \cdot 16(12 \cdot 66,15 \cdot 67)$ & $15 \cdot 36(14 \cdot 10,16 \cdot 63)$ \\
\hline \multicolumn{6}{|l|}{ Sugar } \\
\hline Quintile 1 & 0.00 & 0.00 & 0.00 & 0.00 & 0.00 \\
\hline Quintile 2 & $-8.92(-10.42,-7.43)$ & $-2.68(-4.30,-1.07)$ & $-7.86(-9.34,-6.39)$ & $5.40(3.91,6.88)$ & $5.82(4.23,7.40)$ \\
\hline Quintile 3 & $-13.30(-14.83,-11.77)$ & $-2.16(-3.66,-0.66)$ & $-12.07(-13.68,-10.47)$ & $10.36(8.86,11.87)$ & $9.41(7.85,10.98)$ \\
\hline Quintile 4 & $-16.07(-17.61,-14.53)$ & $-2.45(-4.07,-0.84)$ & $-14.25(-15.87,-12.63)$ & $15.53(13.98,17.08)$ & $11.30(9.71,12.89)$ \\
\hline Quintile 5 & $-22.83(-24.40,-21.27)$ & $-5.46(-7.21,-3.70)$ & $-21.62(-23.20,-20.03)$ & $32.72(31.03,34.41)$ & $10.46(8.94,11.98)$ \\
\hline
\end{tabular}

"All $P<0.0001$, unless otherwise stated. Lowest quintile used as the reference category.

†For details of subjects and procedures, see Subjects and methods. 
NS British Journal of Nutrition

Table 4. Adjusted parameter estimates $(95 \% \mathrm{Cl})$ for micronutrient intakes according to quintiles of dietary pattern score, adjusted for energy intake ${ }^{\star} \dagger$

\begin{tabular}{|c|c|c|c|c|c|}
\hline Micronutrient & 'Health-conscious' & 'Traditional' & 'Processed' & 'Confectionery' & 'Vegetarian' \\
\hline \multicolumn{6}{|l|}{ Fibre } \\
\hline Quintile 1 & 0.00 & 0.00 & 0.00 & 0.00 & 0.00 \\
\hline Quintile 2 & $1.81(1.57,2.05)$ & $1.50(1.22,1.78)$ & $-1.13(-1.40,-0.86)$ & $-0.27(-0.56,0.01)$ & $-0.29(-0.58,-0.01)$ \\
\hline Quintile 3 & $3.47(3.22,3.72)$ & $1.83(1.57,2.09)$ & $-1.72(-2.01,-1.42)$ & $-0.79(-1.08,-0.51)$ & $-0.93(-1.22,-0.65)$ \\
\hline Quintile 4 & $5.38(5.13,5.63)$ & $2.36(2.08,2.64)$ & $-2.64(-2.93,-2.44)$ & $-1.35(-1.64,-1.05)$ & $-0.90(-1.19,-0.61)$ \\
\hline Quintile 5 & $7.97(7.72,8.23)$ & $6.00(5.70,6.30)$ & $-4.13(-4.42,-3.84)$ & $-3.51(-3.84,-3.19)$ & $1.42(1.14,1.70)$ \\
\hline \multicolumn{6}{|l|}{$\mathrm{K}$} \\
\hline Quintile 1 & 0.00 & 0.00 & 0.00 & 0.00 & 0.00 \\
\hline Quintile 2 & $144.5(124 \cdot 8,164 \cdot 2)$ & $140 \cdot 8(120 \cdot 6,161 \cdot 0)$ & $-17.53(-38.42,3.35)$ & $2 \cdot 31(-19 \cdot 26,23 \cdot 89)$ & $-100 \cdot 3(-121 \cdot 9,-78 \cdot 6)$ \\
\hline Quintile 3 & $251.0(230 \cdot 9,271 \cdot 1)$ & $213.5(194 \cdot 8,232 \cdot 2)$ & $-23.68(-46.36,-1.00)$ & $-12.03(-33.89,9.83)$ & $-165.5(-186 \cdot 8,-144 \cdot 2)$ \\
\hline Quintile 4 & $329.8(309.5,350.0)$ & $308.9(288.8,329.1)$ & $-29.94(-52.87,-7.01)$ & $-22.23(-44.81,0.36)$ & $-219.6(-241.3,-197.9)$ \\
\hline Quintile 5 & $438.4(417.7,459.0)$ & $536.0(514.1,587.9)$ & $-74.29(-96.67,-51.90)$ & $-136 \cdot 3(-160 \cdot 9,-111 \cdot 7)$ & $-160 \cdot 0(-180 \cdot 7,-139 \cdot 3)$ \\
\hline \multicolumn{6}{|r|}{ : } \\
\hline Quintile 1 & 0.00 & 0.00 & 0.00 & 0.00 & 0.00 \\
\hline Quintile 2 & $111.9(93.1,130.6)$ & $6 \cdot 86(-13 \cdot 5,27 \cdot 2)$ & $61 \cdot 6(42 \cdot 8,80 \cdot 4)$ & $-39 \cdot 1(-58 \cdot 1,-20 \cdot 1)$ & $12 \cdot 5(-7 \cdot 6,32 \cdot 8)$ \\
\hline Quintile 3 & $161.8(142 \cdot 7,181.0)$ & $-18.7(-37.6,0.2)$ & $104 \cdot 6(84 \cdot 2,125 \cdot 0)$ & $-88.8(-108.0,-69.5)$ & $-15 \cdot 8(-36 \cdot 6,4 \cdot 1)$ \\
\hline Quintile 4 & $212 \cdot 3(193 \cdot 0,231 \cdot 6)$ & $-51.9(-72.2,-31.6)$ & $121.5(100 \cdot 8,142 \cdot 1)$ & $-150.9(-170 \cdot 8,-131.0)$ & $-19.6(-39.8,0.7)$ \\
\hline Quintile 5 & $301.4(281.7,321.1)$ & $-17.4(-39.5,4.7)$ & $215.6(195 \cdot 4,235.7)$ & $-348.4(-370 \cdot 0,-326 \cdot 7)$ & $-9.8(-29.1,9.6)$ \\
\hline \multicolumn{6}{|l|}{$\mathrm{Ca}$} \\
\hline Quintile 1 & 0.00 & 0.00 & 0.00 & 0.00 & 0.00 \\
\hline Quintile 2 & 33.28 (23.21, 43.35) & $8.00(-2.71,18.71)$ & $-11.59(-21.61,-1.57)$ & $-2 \cdot 28(-12 \cdot 64,8.09)$ & $37.26(26 \cdot 68,47 \cdot 84)$ \\
\hline Quintile 3 & $61 \cdot 88(51.58,72 \cdot 18)$ & $13.39(3.46,23.32)$ & $-30.37(-41 \cdot 26,-19 \cdot 49)$ & $-19.56(-30.07,-9.06)$ & $38.37(27.96,48.79)$ \\
\hline Quintile 4 & $87.06(76.69,97.43)$ & $29.33(18.63,40.04)$ & $-37.85(-48.85,-26.84)$ & $-44.07(-54.92,-33.21)$ & $33.70(23.09,44.31)$ \\
\hline Quintile 5 & $115.62(105.06,126.19)$ & $56 \cdot 10(44.46,67.73)$ & $-75 \cdot 38(-86 \cdot 12,-64.63)$ & $-92.98(-104.82,-81.14)$ & $71.51(61.39,81.63)$ \\
\hline \multicolumn{6}{|l|}{$\mathrm{Mg}$} \\
\hline Quintile 1 & 0.00 & 0.00 & 0.00 & 0.00 & 0.00 \\
\hline Quintile 2 & $22.29(20.01,24.57)$ & $10.80(7.88,13.72)$ & $-11.06(-13.75,-8.37)$ & $-3.75(-6.64,-0.87)$ & $-4.52(-7.44,-1.60)$ \\
\hline Quintile 3 & $41.83(39.50,44.17)$ & $13.06(10 \cdot 35,15 \cdot 78)$ & $-18.99(-21.92,-16.07)$ & $-9.28(-12 \cdot 20,-6 \cdot 35)$ & $-11.48(-14.36,-10.23)$ \\
\hline Quintile 4 & $63.67(61.32,66 \cdot 02)$ & $17.86(14.94,20.79)$ & $-29.05(-32.00,-26.09)$ & $-14.64(-17.66,-11.63)$ & $-13.16(-16.09,-10.23)$ \\
\hline Quintile 5 & $93.21(90.82,95.61)$ & $39.62(36.45,42.80)$ & $-47.50(-32.00,-26.09)$ & $-30 \cdot 40(-33 \cdot 70,-27 \cdot 11)$ & $13.67(10.87,16.46)$ \\
\hline \multicolumn{6}{|l|}{$\mathrm{Fe}$} \\
\hline Quintile 1 & 0.00 & 0.00 & 0.00 & 0.00 & 0.00 \\
\hline Quintile 2 & $1.01(0.91,1.12)$ & $0.47(0.35,0.60)$ & $-0.45(-0.56,-0.33)$ & $-0.19(-0.32,-0.07)$ & $-0.33(-0.46,-0.21)$ \\
\hline Quintile 3 & $1.79(1.64,1.90)$ & $0.57(0.45,0.69)$ & $-0.69(-0.82,-0.56)$ & $-0.44(-0.57,-0.31)$ & $-0.66(-0.78,-0.53)$ \\
\hline Quintile 4 & $2.56(2.45,2.67)$ & $0.69(0.57,0.82)$ & $-1.04(-1.17,-0.91)$ & $-0.65(-0.78,-0.52)$ & $-0.70(-0.83,-0.57)$ \\
\hline Quintile 5 & $3.60(3.49,3.71)$ & $1.81(1.68,1.95)$ & $-1.49(-1.61,-1.36)$ & $-1.33(-1.48,-1.19)$ & $0.01(-0.11,0.13)$ \\
\hline \multicolumn{6}{|l|}{$\mathrm{Zn}$} \\
\hline Quintile 1 & 0.00 & 0.00 & 0.00 & 0.00 & 0.00 \\
\hline Quintile 2 & $0.79(0.72,0.86)$ & $0.38(0.30,0.46)$ & $-0.10(-0.18,-0.02)$ & $-0.30(-0.38,-0.22)$ & $-0.99(-1.07,-0.91)$ \\
\hline Quintile 3 & $1.32(1.25,1.39)$ & $0.48(0.41,0.56)$ & $-0.16(-0.25,-0.07)$ & $-0.53(-0.61,-0.45)$ & $-1.37(-1.45,-1.29)$ \\
\hline Quintile 4 & $1.85(1.78,1.92)$ & $0.70(0.62,0.79)$ & $-0.30(-0.39,-0.21)$ & $-0.76(-0.85,-0.68)$ & $-1.64(-1.72,-1.57)$ \\
\hline Quintile 5 & $2.51(2.44,2.59)$ & $1.29(1.19,1.38)$ & $-0.47(-0.56,-0.39)$ & $-1.49(-1.59,-1.41)$ & $-1.60(-1.67,-1.52)$ \\
\hline \multicolumn{6}{|l|}{ Vitamin C } \\
\hline Quintile 1 & 0.00 & 0.00 & 0.00 & 0.00 & 0.00 \\
\hline Quintile 2 & $93.1(81.9,104.3)$ & $91.6(79.6,103 \cdot 7)$ & $-74.5(-86.5,-62.4)$ & $-5.08(-18.13,-7.98)$ & $-31.79(-44.97,-18.62)$ \\
\hline Quintile 3 & $167.5(156 \cdot 0,179 \cdot 0)$ & $113.4(102 \cdot 3,124.5)$ & $-113 \cdot 4(-126 \cdot 5,-100 \cdot 3)$ & $-9.77(-22.99,3.45)$ & $-61.57(-74.35,-48.40)$ \\
\hline Quintile 4 & $233 \cdot 6(222 \cdot 1,245 \cdot 2)$ & $137 \cdot 6(125 \cdot 6,149 \cdot 6)$ & $-146.0(-159.2,-132.8)$ & $3.83(-9.84,17.49)$ & $-80.99(-94.20,-67.78)$ \\
\hline Quintile 5 & $336.0(324.7,347.7)$ & $346.8(333.8,359.9)$ & $-213 \cdot 2(-226 \cdot 2,-200 \cdot 3)$ & $-46.72(-61.62,-31.81)$ & $-15.25(-27.85,-2.65)$ \\
\hline \multicolumn{6}{|l|}{ Folate } \\
\hline Quintile 1 & 0.00 & 0.00 & 0.00 & 0.00 & 0.00 \\
\hline Quintile 2 & $21.2(18.4,23.9)$ & $21 \cdot 8(19 \cdot 0,24 \cdot 5)$ & $-9.9(-12.9,-7.1)$ & $-2 \cdot 1(-5 \cdot 2,0.9)$ & $-5.5(-8 \cdot 6,-2 \cdot 3)$ \\
\hline Quintile 3 & $37.7(34.9,40.5)$ & $30.7(28.2,33.3)$ & $-16.5(-19.7,-13.4)$ & $-7.6(-10.6,-4.5)$ & $-13.3(-16 \cdot 4,-10.3)$ \\
\hline
\end{tabular}


Table 4. Continued

\begin{tabular}{|c|c|c|c|c|c|}
\hline Micronutrient & 'Health-conscious' & 'Traditional' & 'Processed' & 'Confectionery' & 'Vegetarian' \\
\hline Quintile 4 & $52 \cdot 2(49 \cdot 4,55 \cdot 0)$ & $39 \cdot 3(36 \cdot 6,42 \cdot 1)$ & $-22 \cdot 7(-25 \cdot 9,-19 \cdot 6)$ & $-11.4(-14.5,-8.2)$ & $-17 \cdot 1(-20 \cdot 2,-13 \cdot 9)$ \\
\hline Quintile 5 & $70.3(67.4,73.1)$ & $91.4(88.4,94.4)$ & $-38.1(-41.2,-35.0)$ & $-31 \cdot 8(-35 \cdot 2,-28 \cdot 3)$ & $-2.0(-5.0,1.0)$ \\
\hline \multicolumn{6}{|l|}{ Carotene } \\
\hline Quintile 1 & 0.00 & 0.00 & 0.00 & 0.00 & 0.00 \\
\hline Quintile 2 & $171.0(107 \cdot 8,234 \cdot 2)$ & $592 \cdot 6(546 \cdot 0,639 \cdot 1)$ & $-225 \cdot 3(-287 \cdot 5,-163 \cdot 1)$ & $-122.9(-188.1,-57.8)$ & $-164.4(-230.5,-97.9)$ \\
\hline Quintile 3 & $321.3(256 \cdot 6,285.9)$ & $875.2(832.0,918.4)$ & $-350.4(-417.9,-282.9)$ & $-198 \cdot 2(-264 \cdot 2,-132 \cdot 2)$ & $-240.9(-306 \cdot 1,-175 \cdot 6)$ \\
\hline Quintile 4 & $476.6(411.5,541.7)$ & $1213 \cdot 7(1167 \cdot 2,1260 \cdot 3)$ & $-420 \cdot 3(-488 \cdot 6,-352 \cdot 0)$ & $-280 \cdot 4(-348 \cdot 6,-212 \cdot 2)$ & $-306 \cdot 7(-373 \cdot 1,-240 \cdot 3)$ \\
\hline Quintile 5 & $610.8(544.5,677 \cdot 1)$ & $2780.8(2730.2,2831.4)$ & $-619.8(-686 \cdot 5,-553 \cdot 1)$ & $-456.9(-531.3,-382.5)$ & $-91.9(-155.3,-28.6)$ \\
\hline \multicolumn{6}{|c|}{ (1) } \\
\hline Quintile 1 & 0.00 & 0.00 & 0.00 & 0.00 & 0.00 \\
\hline Quintile 2 & $-1.97(-20.95,17.00)$ & $-0.31(-20.11,19.49)$ & $32.52(14.03,50.99)$ & $-80.1(-99.11,-61.06)$ & $16.23(-3.40,35 \cdot 87)$ \\
\hline Quintile 3 & $-0.05(-19.46,19.36)$ & $17.43(-0.94,35.79)$ & $64.99(44.91,85.06)$ & $-102 \cdot 6(-121 \cdot 8,-83.3)$ & $30.43(11.10,49.75)$ \\
\hline Quintile 4 & $-8.92(-28.46,10.62)$ & $41.05(21.26,60.85)$ & $68.55(48.26,88.85)$ & $-143 \cdot 6(-163 \cdot 5,-123 \cdot 7)$ & $43.63(23.95,63.31)$ \\
\hline Quintile 5 & $\begin{array}{l}-28.49(-48.39,-8.58) \\
0.022\end{array}$ & $20.86(-0.66,42.38)$ & $135 \cdot 7(115 \cdot 9,115 \cdot 6)$ & $-220 \cdot 5(-242 \cdot 2,-198 \cdot 7)$ & $10.34(-8.44,29.11)$ \\
\hline \multicolumn{6}{|l|}{ Vitamin E } \\
\hline Quintile 1 & 0.00 & 0.00 & 0.00 & 0.00 & 0.00 \\
\hline Quintile 2 & $0.39(0.18,0.59)$ & $0.24(0.03,0.46)$ & $-0.27(-0.47,-0.07)$ & $-0.17(-0.38,0.04)$ & $0.25(0.04,0.47)$ \\
\hline Quintile 3 & $0.74(0.53,0.95)$ & $0.23(0.03,0.43)$ & $-0.62(-0.84,-0.40)$ & $-0.36(-0.58,-0.15)$ & $0.21(0.00,0.42)$ \\
\hline Quintile 4 & $1.13(0.92,1.35)$ & $0.30(0.08,0.52)$ & $-0.88(-1.10,-0.65)$ & $-0.84(-1.06,-0.62)$ & $0.45(0.23,0.66)$ \\
\hline Quintile 5 & $1.68(1.46,1.90)$ & $0.80(0.57,1.04)$ & $-1.37(-1.59,1.16)$ & $-1.53(-1.77,-1.29)$ & $1.33(1.12,1.53)$ \\
\hline \multicolumn{6}{|l|}{ Thiamine } \\
\hline Quintile 1 & 0.00 & 0.00 & 0.00 & 0.00 & 0.00 \\
\hline Quintile 2 & $0.12(0.11,0.14)$ & $0.08(0.06,0.10)$ & $-0.04(-0.05,-0.02)$ & $-0.01(-0.03,0.00)$ & $-0.09(-0.11,-0.08)$ \\
\hline Quintile 3 & $0.21(0.20,0.22)$ & $0.11(0.09,0.12)$ & $-0.07(-0.09,-0.05)$ & $-0.05(-0.06,-0.03)$ & $-0.16(-0.17,-0.14)$ \\
\hline Quintile 4 & $0.29(0.28,0.30)$ & $0.16(0.14,0.17)$ & $-0.10(-0.12,-0.09)$ & $-0.08(0.10,-0.06)$ & $-0.18(-0.20,-0.17)$ \\
\hline Quintile 5 & $0.41(0.39,0.42)$ & $0.31(0.29,0.32)$ & $-0.19(-0.21,-0.17)$ & $-0.22(-0.23,-0.20)$ & $-0.10(-0.11,-0.08)$ \\
\hline \multicolumn{6}{|l|}{ Niacin } \\
\hline Quintile 1 & 0.00 & 0.00 & 0.00 & 0.00 & 0.00 \\
\hline Quintile 2 & $1.96(1.78,2.15)$ & $0.87(0.65,1.08)$ & $-0.23(-0.44,-0.03)$ & $-0.48(-0.69,-0.27)$ & $-2.05(-2.26,-1.85)$ \\
\hline Quintile 3 & $3.16(2.97,3.35)$ & $1.08(0.87,1.28)$ & $-0.42(-0.65,-0.20)$ & $-0.90(-1.11,-0.68)$ & $-3.04(-3.24,-2.84)$ \\
\hline Quintile 4 & $4.29(4.10,4.48)$ & $1.45(1.24,1.67)$ & $-0.83(-1.06,-0.60)$ & $-1.19(-1.41,-0.96)$ & $-3.83(-4.03,-3.63)$ \\
\hline Quintile 5 & $5.80(5.61,6.00)$ & $2.89(2.65,3.12)$ & $-1.48(-1.70,-1.26)$ & $-2.93(-3.18,-2.69)$ & $-4.13(-4.33,-3.94)$ \\
\hline \multicolumn{6}{|l|}{ Riboflavin } \\
\hline Quintile 1 & 0.00 & 0.00 & 0.00 & 0.00 & 0.00 \\
\hline Quintile 2 & $0.09(0.07,0.12)$ & $0.03(0.01,0.05)$ & $-0.04(-0.06,-0.01)$ & $-0.01(-0.03,0.02)$ & $-0.01(-0.04,0.01)$ \\
\hline Quintile 3 & $0.16(0.14,0.18)$ & $0.06(0.04,0.08)$ & $-0.07(-0.09,-0.05)$ & $-0.03(-0.05,-0.01)$ & $-0.05(-0.07,-0.03)$ \\
\hline Quintile 4 & $0.19(0.17,0.21)$ & $0.10(0.07,0.12)$ & $-0.09(-0.12,-0.07)$ & $-0.06(-0.08,-0.03)$ & $-0.07(-0.09,-0.05)$ \\
\hline Quintile 5 & $0.21(0.19,0.23)$ & $0.14(0.12,0.17)$ & $-0.17(-0.19,-0.14)$ & $-0.13(-0.16,-0.11)$ & $-0.10(-0.12,-0.08)$ \\
\hline \multicolumn{6}{|l|}{ Vitamin B6 } \\
\hline Quintile 1 & 0.00 & 0.00 & 0.00 & 0.00 & 0.00 \\
\hline Quintile 2 & $0.16(0.14,0.18)$ & $0.11(0.09,0.14)$ & $-0.02(-0.04,0.01)$ & $-0.02(-0.04,0.01)$ & $-0.10(-0.12,-0.08)$ \\
\hline Quintile 3 & $0.27(0.25,0.29)$ & $0.17(0.15,0.19)$ & $-0.04(-0.06,-0.02)$ & $-0.06(-0.08,-0.04)$ & $-0.18(-0.20,-0.16)$ \\
\hline Quintile 4 & $0.34(0.32,0.36)$ & $0.24(0.22,0.26)$ & $-0.06(-0.08,-0.04)$ & $-0.09(-0.11,-0.07)$ & $-0.22(-0.25,-0.20)$ \\
\hline Quintile 5 & $0.46(0.44,0.48)$ & $0.43(0.41,0.45)$ & $-0.13(-0.15,-0.11)$ & $-0.25(-0.28,-0.23)$ & $-0.21(-0.23,-0.19)$ \\
\hline
\end{tabular}


standard' method of collecting - weighed dietary records. However, one major advantage of the present study is the large sample size; weighed intake in such a sample would have been expensive and a greater burden for the participants, potentially increasing bias in the sample. The nutrient intakes in this sample have been shown to compare favourably with the intakes reported by the last Dietary and Nutritional Survey of British adults for all women aged 16-64 years, where food intake was weighed for $7 \mathrm{~d}^{13}$. Several studies have compared the results of PCA using FFQ with those using weighed dietary records $7,37,38$. They all concluded that the resulting factor loadings and dietary pattern scores were comparable.

When investigating diet-disease associations, the use of dietary patterns offers advantages over the usual methods of examining single foods or nutrients. The primary benefit of using patterns is the ability to compensate for the substantial inter-correlations between individual food and nutrient intakes. It would appear from the results presented here that the dietary patterns identified in this study adequately characterize actual dietary intake. We therefore believe it is reasonable to suggest that dietary patterns are a valid tool in assessing the relationship between diet and health outcomes, at least in preliminary investigations. It also reinforces the suggestion made by Hu et al. that patterns could be used as an additional covariate in specific nutrient-disease studies, in order to take account of overall patterns in dietary intake ${ }^{4}$.

With the exception of energy, all the nutrients investigated here were lower in the highest quintile of the 'processed' and 'confectionery' components and were highest in the top quintile of the 'health conscious' and 'traditional' components. This suggests that characteristics of these patterns could be used to formulate guidelines for pregnant women. Inadequate intake of various individual nutrients has been implicated in reduced birth weight, although the evidence is inconclusive, and in poor birth outcomes such as neural tube defects. We plan to build on this work by investigating the associations between dietary patterns and birth outcomes.

\section{Acknowledgements}

We are extremely grateful to all the families who took part in this study, the midwives for their help in recruiting them and the whole ALSPAC team, which includes interviewers, computer and laboratory technicians, clerical workers, research scientists, volunteers, managers, receptionists and nurses. The UK Medical Research Council, the Wellcome Trust and the University of Bristol provide core support for ALSPAC. This work was also partially funded by a Wellcome Trust VIP award to K.N. and by the Arthritic Association supporting K.N. and P.M.E. This publication is the work of the authors, who also serve as guarantors for the contents of this paper. We declare there is no conflict of interest.

\section{References}

1. Martinez ME, Marshall JR \& Sechrest L (1998) Invited Commentary: factor analysis and the search for objectivity. Am J Epidemiol 148, 17-19.

2. Jacques PF \& Tucker KL (2001) Editorial: are dietary patterns useful for understanding the role of diet in chronic disease? Am $J$ Clin Nutr 73, 1-2.
3. Trichopoulos D \& Lagiou P (2001) Invited commentary: dietary patterns and mortality. Br J Nutr 85, 133-134.

4. Hu FB (2002) Dietary pattern analysis: a new direction in nutritional epidemiology. Curr Opin Lipidol 13, 3-9.

5. Schulze MB, Hoffmann K, Kroke A \& Boeing H (2001) Dietary patterns and their association with food and nutrient intake in the European Prospective Investigation into cancer and Nutrition (EPIC) - Postdam study. Br J Nutr 85, 363-373.

6. Randall E, Marshall JR, Graham S \& Brasure J (1990) Patterns in food use and their associations with nutrient intakes. Am J Clin Nutr 52, 739-745.

7. $\mathrm{Hu}$ FB, Smith-Warner SA, Feskanich MJ, Stampfer MJ, Ascherio A, Sampson L \& Willett WC (1999) Reproducibility and validity of dietary patterns assessed with a food-frequency questionnaire. Am J Clin Nutr 69, 243-249.

8. Crozier SR, Robinson SM, Borland SM, Inskip HM \& the SWS Study Group (2006) Dietary patterns in the Southampton Women's Survey. Eur J Clin Nutr 60, 1391-1399.

9. Newby PK, Muller D, Hallfrisch J, Andres R \& Tucker KL (2004) Food patterns measured by factor analysis and anthropometric changes in adults. Am J Clin Nutr 80, 504-513.

10. Mikkila V, Rasanen L, Raitakari OT, Pietinen P \& Viikari J (2005) Consistent dietary patterns identified from childhood to adulthood: the cardiovascular risk in young Finns Study. $\mathrm{Br} J$ Nutr 93, 923-931.

11. Golding J, Pembrey M, Jones R \& ALSPAC Study Team (2001) ALSPAC - the Avon Longitudinal Study of Parents and Children I. Study methodology. Paediatr Perinatal Epidemiol 15, $74-87$.

12. Rogers IS, Emmett PM \& the ALSPAC Study Team (1998) Diet during pregnancy in a population of pregnant women in South West England. Eur J Clin Nutr 52, 246-250.

13. Gregory J, Foster K, Tyler H \& Wiseman M (1990) The Dietary and Nutritional Survey of British Adults. London: HMSO.

14. Williams C, Birch EE, Emmett PM, Northstone K \& the ALSPAC "Children in Focus" Study Team (2001) Steroacuity at 3.5 years of age in children born full term is associated with prenatal and postnatal dietary factors; an early report from a population based study. Am J Clin Nutr 73, 316-322.

15. The Royal Society of Chemistry \& MAFF (1988) Cereals and Oat Products. London: HMSO.

16. The Royal Society of Chemistry \& MAFF (1989) Milk Products and Eggs. London: HMSO.

17. The Royal Society of Chemistry \& MAFF (1991) The Composition of Foods, 5th edition. London: HMSO.

18. The Royal Society of Chemistry \& MAFF (1991) Vegetables, Herbs and Spices. London: HMSO.

19. The Royal Society of Chemistry \& MAFF (1992) Fruits and Nuts. London: HMSO.

20. The Royal Society of Chemistry \& MAFF (1992) Vegetable Dishes. London: HMSO.

21. The Royal Society of Chemistry \& MAFF (1993) Fish and Fish Products. London: HMSO.

22. Ministry of Agriculture, Fisheries and Foods (1993) Food Portion Sizes, 2nd edition. London: The Stationery Office.

23. Northstone K, Emmett P \& Rogers I (2007) Dietary patterns in pregnancy and associations with socio-demographic and lifestyle factors. Eur J Clin Nutr. doi.10.1038/sj.ejcn.1602741.

24. Gorsuch RL (1974) Factor Analyses. Philadelphia: W.B. Saunders.

25. Kline P (1994) An Easy Guide to Factor Analysis. London: Routledge.

26. Cattell RB (1966) The scree test for the number of factors. Multivariate Behav Res 1, 245-276.

27. Bland M (2000) An Introduction to Medical Statistics, 3rd edition. Oxford: Oxford University Press. 
28. Balder HF, Virtanen M, Brants HAM, et al. (2003) Common and country-specific dietary patterns in four European cohort studies. J Nutr 133, 4246-4251.

29. Bamia C, Orfanos P, Ferrari P, Overvad K, Hundborg HH, Tjonneland A \& Olsen A (2005) Dietary patterns among older Europeans: the EPIC-elderly study. Br J Nutr 94, 100-113.

30. Newby PK, Muller D, Hallfrisch J, Qiao N, Andres R \& Tucker KL (2003) Dietary patterns and changes in body mass index and waist circumference in adults. Am J Clin Nutr 77, 1417-1425.

31. Northstone K, Ness AR, Emmett PM \& Rogers IS (2007) Adjusting for energy intake in dietary pattern investigations using principal components analysis. Eur J Clin Nutr. doi:10.1038/ sj.ejcn.1602789.

32. Wolff CB \& Wolff HK (1995) Maternal eating patterns and birth weight of Mexican American infants. Nutrition and Health 10, 121-134.

33. Cuco G, Fernandez-Ballart J, Sala J, Viladrich C, Iranzo R, Vila J \& Arija V (2006) Dietary patterns and associated lifestyles in preconception, pregnancy and postpartum. Eur J Clin Nutr 60, 364-371.
34. Knudsen VK, Orozova-Bekkevold IM, Mikkelsen TB \& Olsen SF (2007) Major dietary patterns in pregnancy and fetal growth. Eur J Clin Nutr, Published online: doi.101038/ sj.ejen. 1602745 .

35. Department of Health (1991) Dietary Reference Values for Food, Energy and Nutrients For the United Kingdom. Report on health and social subjects. London: HMSO.

36. Hoffman KSM, Schienkiewtz A, Nothlings U \& Boeing $\mathrm{H}$ (2004) Application of a new statistical method to derive dietary patterns in nutritional epidemiology. Am J Epidemiol 159, 935-944.

37. Khani BR, Ye W, Terry P \& Wolk A (2004) Reproducibility and validity of major dietary patterns among Swedish women assessed with a food-frequency questionnaire. J Nutr 134, $1541-1545$

38. Togo P, Heitmann BL, Sorensen TIA \& Osler M (2003) Consistency of food intake factors by different dietary assessment methods and population groups. Br J Nutr 90, 667-678. 